\title{
Effects of Helicobacter pylori Infection on the Link between Regenerating Gene Expression and Serum Gastrin Levels in Mongolian Gerbils
}

\author{
Hirokazu Fukui, Francesco Franceschi, Rebecca L. Penland, Taro Sakai, \\ Antonia R. Sepulveda, Takahiro Fujimori, Akira Terano, Tsutomu Chiba, and \\ Robert M. Genta
}

Department of Pathology, Medicine, and Microbiology and Immunology (HF, FF, RLP, TS, ARS, RMG), Veterans Affairs Medical Center and Baylor College of Medicine, Houston, Texas; Departments of Pathology (HF, TS, TF) and Gastroenterology (AT), Dokkyo University School of Medicine, Tochigi, and Department of Gastroenterology and Hepatology (HF, TC), Kyoto University Graduate School of Medicine, Kyoto, Japan

\begin{abstract}
SUMMARY: Although regenerating gene (Reg) protein is reported to have a trophic effect on gastric epithelial cells, its involvement in human gastric diseases is not clear. We have recently shown that both gastrin and gastric mucosal inflammation enhance Reg gene expression in the fundic mucosa in rats. This study was designed to clarify whether Reg protein is involved in Helicobacter pylori-induced gastritis and whether Reg gene expression is linked to serum gastrin levels in this condition. Mongolian gerbils were inoculated with an $H$. pylori strain isolated from a gastric cancer patient. Four weeks later, some of the gerbils with $H$. pylori infection were eradicated by lansoprazole, amoxicillin, and clarithromycin. The time courses of changes in Reg gene expression, serum gastrin levels, gastric acidity, and histopathologic factors were examined. Four weeks after $H$. pylori infection, gastritis started spreading to the fundic mucosa, and gastric acidity started reducing. Serum gastrin levels and Reg mRNA expression in the fundus were significantly increased 6 weeks after infection. Reg mRNA expression in the fundus correlated significantly with both serum gastrin levels and the severity of fundic mucosal inflammation. After $H$. pylori eradication, serum gastrin levels and fundic mucosal inflammation were normalized, and the increase in Reg mRNA expression was abolished. The Reg gene is associated with hypergastrinemia and fundic mucosal inflammation and may be involved in $\mathrm{H}$. pylori-induced gastritis. (Lab Invest 2003, 83:1777-1786).
\end{abstract}

$T$ he regenerating gene $(R e g)$ was isolated from a cDNA library derived from regenerating rat pancreatic islets (Terazono et al, 1988). Thereafter, Reg protein was found to be identical to pancreatic stone protein, lithostathine, and pancreatic thread protein, all of which had been discovered independently and were given several different names (De Caro et al, 1987; Giorgi et al, 1989; Rouquier et al, 1989). Subsequently, Watanabe et al (1994) found that Reg protein is mitogenic to islet cells and suggested that it may be an endogenous growth factor in pancreatic islets. Recently, we showed that Reg protein is overexpressed in enterochromaffin-like (ECL) cells during the healing of gastric ulcer lesions (Asahara et al, 1996;

DOI: 10.1097/01.LAB.0000106501.56339.CE

Received April 2, 2003.

This work was supported by the Department of Veterans Affairs, Washington, D.C., and by an unrestricted grant from Otsuka Pharmaceuticals, Osaka, Japan. Dr. Fukui is supported by an educational grant from Otsuka Pharmaceuticals and by the Department of Pathology, Dokkyo University School of Medicine, Tochigi, Japan.

Address reprint requests to: Dr. Tsutomu Chiba, Department of Gastroenterology and Hepatology, Kyoto University Graduate School of Medicine, 54, Kawaramachi-shogoin, Sakyo-ku, Kyoto 606-8507, Japan. E-mail: cteya@kuhp.kyoto-u.ac.jp
Kawanami et al, 1997) and suggested that it has a trophic effect on gastric epithelial cells (Fukui et al, 1998). However, the involvement of Reg protein in gastric disease remains unclear.

Helicobacter pylori has been identified as a major pathogen involved in the development of chronic gastritis and gastroduodenal ulcer disease as well as gastric adenocarcinoma (Marshall and Warren, 1984; Parsonnet et al, 1991). Many investigators have carried out intensive studies on the pathophysiology of $H$. pylori-induced gastritis, as this may lead to gastric ulcer and adenocarcinoma. H. pylori infection is known to induce various biological and immunological responses in the stomach. For example, serum levels of gastrin, which regulate gastric acid secretion and have a trophic effect on gastric ECL cells (Hersey and Sachs 1995; Kinoshita et al, 1998), are elevated in patients with chronic gastritis induced by $\mathrm{H}$. pylori infection (Calam, 1996; McGowan et al, 1996). We have previously shown that gastrin acts as an endogenous stimulant for Reg expression in ECL cells (Fukui et al, 1998). In addition, we and other investigators have shown that some cytokines also enhance Reg expression in vivo and in vitro (Akiyama et al, 2001; Dusetti et al, 1996; Kazumori et al, 2000). These data suggest that Reg may be involved in the pathophysi- 


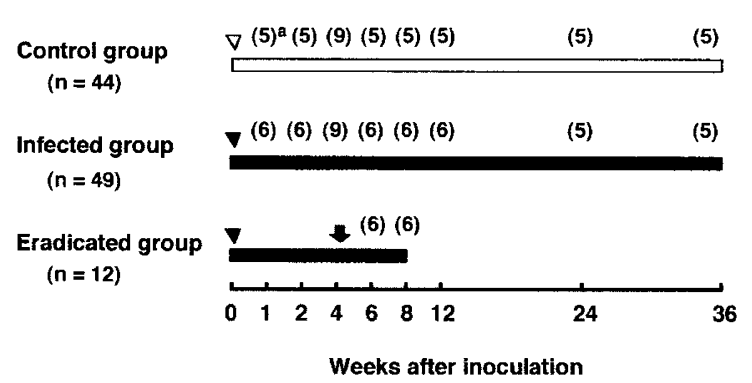

Figure 1.

Schedule of the study. Mongolian gerbils received either brain-heart infusion broth containing Helicobacter pylori (black triangles) or brain-heart infusion broth alone (white triangle). A subgroup of the infected gerbils underwent $H$. pylori eradication using lansoprazole, amoxicillin, and clarithromycin (black

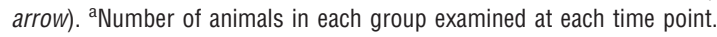

ology of $H$. pylori-induced gastritis. Accordingly, the present study was designed to investigate the effect of H. pylori infection on Reg expression in Mongolian gerbils and to elucidate the role of Reg in the development of gastritis.
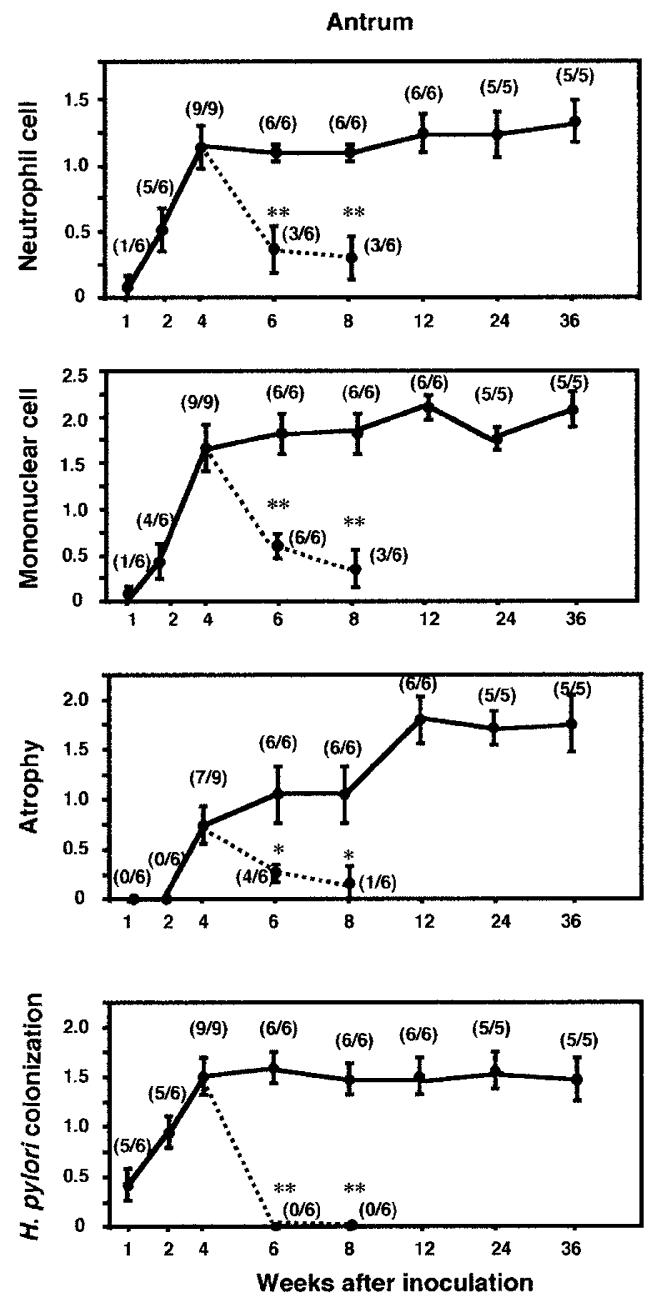

\section{Results}

Effect of $\mathrm{H}$. pylori Infection on Histopathologic Findings

The experimental schedules, including the number of gerbils in each group killed at each time point, are summarized in Figure 1. The uninfected control animals showed no histopathologic abnormalities throughout the observation period. The histopathologic changes occurring in the gastric antrum and corpus of $H$. pylori-infected gerbils for up to 36 weeks are shown in Figure 2.

\section{Neutrophils and Mononuclear Cells}

At 1 week after $H$. pylori inoculation, the gastric mucosa showed almost no histologic changes. At 2 weeks after inoculation, mild inflammatory cell infiltration became apparent in the lamina propria of the antrum, especially in the area close to the pyloric ring (Figs. 2 and 3, A and B); however, no remarkable infiltration of inflammatory cells was observed in the
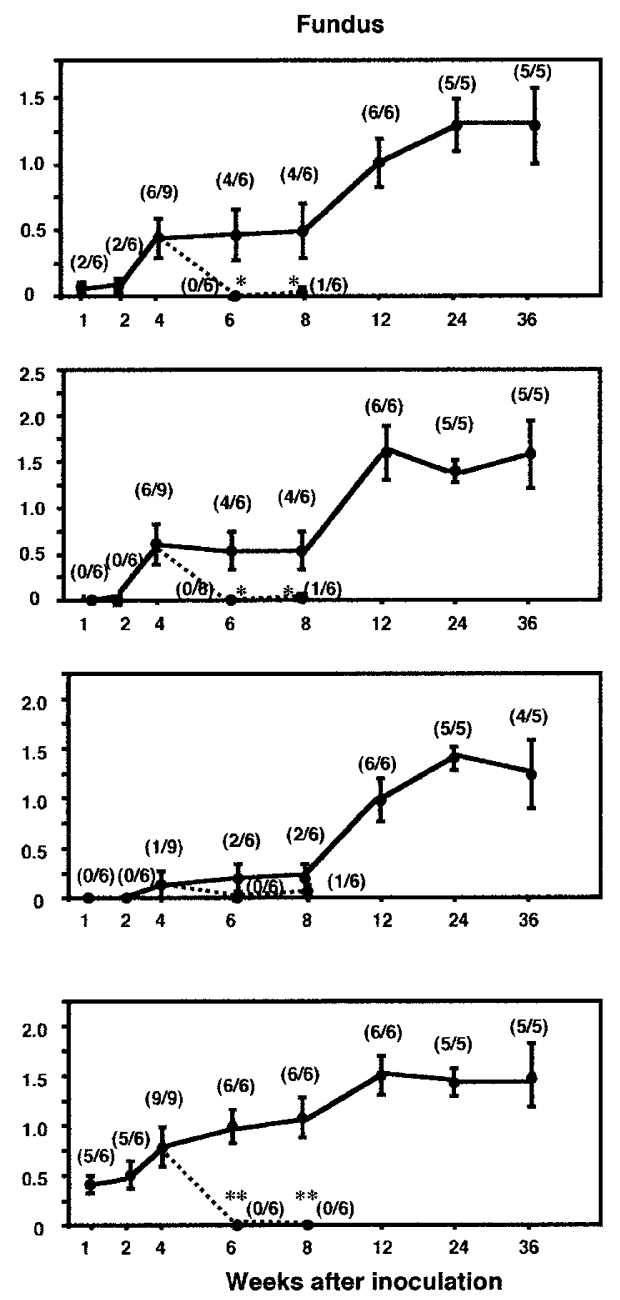

Figure 2.

Serial gastric inflammation, atrophy, and Helicobacter pylori colonization scores in Mongolian gerbils infected with $H$. pylori (-0) and after $H$. pylori eradication (-...). Histologic findings and H. pylori colonization in the antrum and fundus were scored from 0 to 3, as described in the "Materials and Methods" section. Values are expressed as the mean \pm SEM. The numbers in parentheses are the incidences of positive findings. ${ }^{*} p<0.05,{ }^{\star \star} p<0.01$ vs infected group at the same time point. 

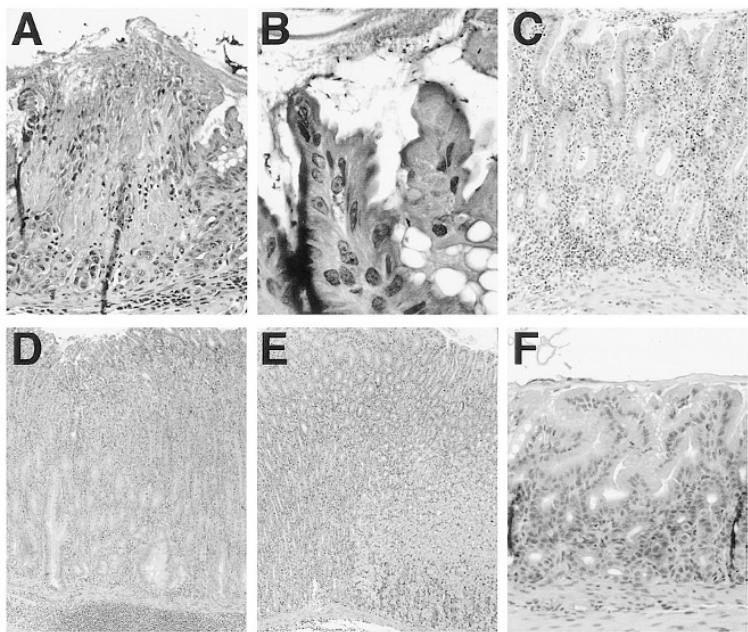

E

F
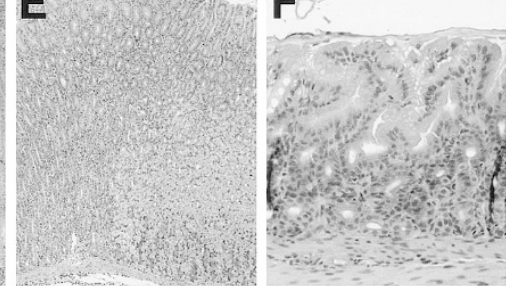

Figure 3.

Histologic findings in the stomachs of Mongolian gerbils infected with Helicobacter pylori and after $\mathrm{H}$. pylori eradication. (A) Focal infiltration of neutrophils and mononuclear cells can be seen in the antral mucosa (close to the pyloric ring) 2 weeks after infection (Genta's staining, $\times 200$ ). (B) At 2 weeks after infection, H. pyloriare present in the destroyed gastric pits and the surface mucous layer (Genta's staining, $\times 1000$ ). (C) Antral mucosa of gerbils infected with $\mathrm{H}$. pyloriat 4 weeks. Inflammatory cells have infiltrated the lamina propria and formed microabscesses (hematoxylin and eosin, $\times 200$ ). (D) Fundic mucosa of gerbils infected with $\mathrm{H}$. pylori at 12 weeks. Elongated glands and a submucosal lymphoid follicle can be seen (hematoxylin and eosin, $\times 100)$. (E) The border of the inflammatory and atrophic lesions in the fundic mucosa of an infected gerbil at 12 weeks. On the anal side (left side of panel), inflammatory cells have infiltrated, and the parietal cells have been destroyed. On the oral side (right side of panel), the epithelium has remained normal (hematoxylin and eosin, $\times 100$ ). (F) Antral mucosa of gerbils 4 weeks after $H$. pylori eradication. In comparison with $\mathrm{C}$, the inflammation is vastly improved and the epithelial structure has been recovered (hematoxylin and eosin, $\times 200)$.

mucosa of the corpus. The inflammation in the antrum peaked at 4 weeks after inoculation (Figs. 2 and 3C), whereas inflammation was only just starting to appear in the corpus at this time, reaching its peak at 12 weeks after inoculation (Figs. 2 and 3D). As shown in Figure $3 \mathrm{E}$, the inflammation spread from the pyloric to the fundic mucosa. The inflammatory cell infiltration scores in both the antrum and the fundus were significantly reduced in gerbils that had undergone $H$. pylori eradication (Figs. 2 and 3 F).

\section{Atrophy}

Following inflammatory cell infiltration, atrophy of the gastric mucosa was observed in the antrum of $H$. pylori-infected gerbils at 4 weeks after inoculation (Figs. 2 and 3C), whereas no remarkable atrophy was observed in the fundus at this time point. Atrophy of the fundic mucosa started to become apparent at 12 weeks after inoculation (Figs. 2 and 3D). The atrophy score in the antrum was significantly reduced in gerbils that had undergone $H$. pylori eradication (Figs. 2 and $3 F$ ).

\section{H. pylori Colonization}

The density of $H$. pylori colonization in the antrum and the fundus peaked at 4 and 12 weeks after inoculation, respectively. H. pylori colonization was not detected in the antrum nor the fundus of gerbils that had undergone $H$. pylori eradication (Fig. 2). H. pylori infection and its disappearance after eradication were also confirmed by culture method.

\section{Gastric Acidity}

At 1 week after inoculation, there was no difference in gastric acidity between the control and infected gerbils. However, at 2 weeks after inoculation, gastric acidity was significantly elevated in the $H$. pyloriinfected group. Interestingly, gastric acidity then decreased in the $H$. pylori-infected gerbils, becoming significantly lower than in the control group at 4 weeks after inoculation and remaining significantly lower thereafter (Fig. 4). At 2 weeks after H. pylori eradication, gastric acidity increased almost up to the control level, and this recovery was sustained until 4 weeks after eradication (Fig. 4).

\section{Serum Gastrin}

Up to 4 weeks after inoculation, there was no significant difference in serum gastrin levels between the control and infected gerbils. However, from 6 weeks after $H$. pylori infection, the serum gastrin level started to increase significantly in the $\mathrm{H}$. pylori-infected gerbils, reaching a peak at 24 weeks after inoculation, and remaining elevated at 36 weeks (Fig. 5). This increase in serum gastrin levels was inhibited by $H$. pylori eradication (Fig. 5).

\section{Fundic Argyrophil Cells and Reg-Positive Cells}

Very few argyrophil cells were detected in the basal regions of the fundic glands in the normal gastric mucosa (Fig. 6A), and there was no significant difference in the number of fundic argyrophil cells between the control and infected gerbils at 4 weeks after inoculation (Fig. 6C). However, the number of argyrophil cells was significantly increased in $\mathrm{H}$. pylori-

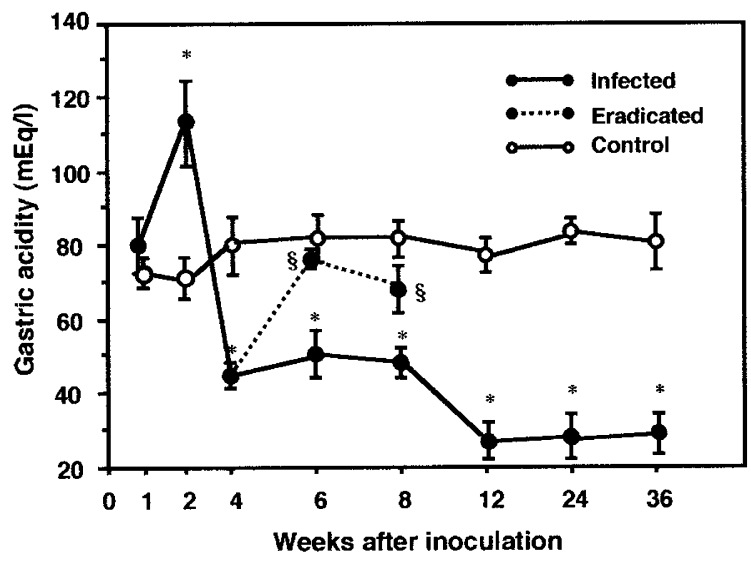

Figure 4.

Serial gastric acidity results in Mongolian gerbils infected with Helicobacter pylori and after $H$. pylori eradication. All results are expressed as the mean \pm SEM. ${ }^{*} p<0.01$ vs control group at the same time point. ${ }^{\S} p<0.05$ vs infected group at the same time point. 


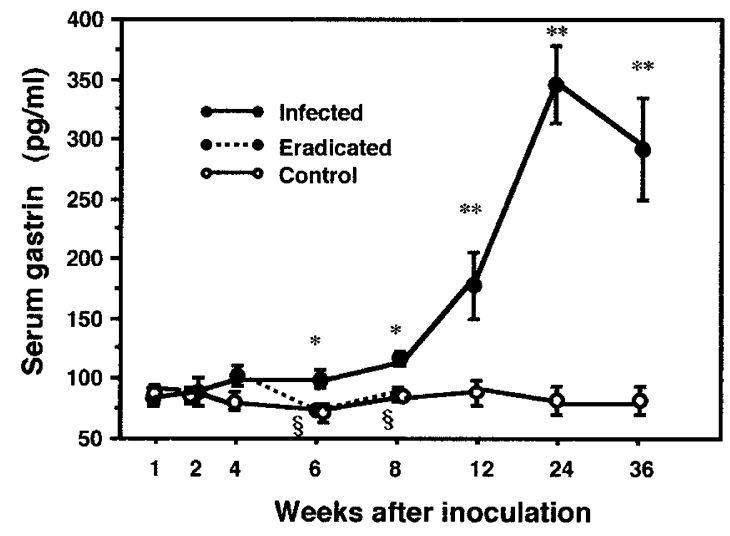

Figure 5.

Serial serum gastrin levels in Mongolian gerbils infected with Helicobacter pylori and after $H$. pylori eradication. All results are expressed as the mean \pm SEM. ${ }^{*} p<0.05,{ }^{* *} p<0.01$ vs control group at the same time point. ${ }^{\circledR} p<0.05$ vs infected group at the same time point.
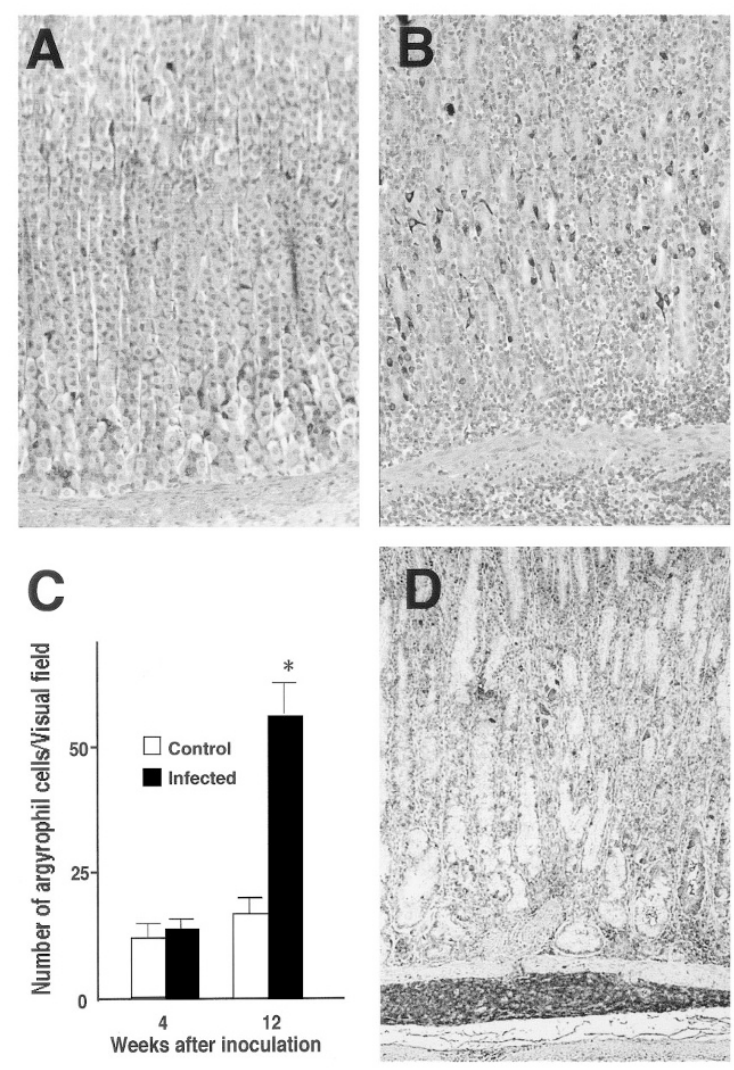

Figure 6.

Silver staining for fundic argyrophil cells. (A) Normal fundic mucosa. (B) Fundic mucosa of Mongolian gerbil infected with Helicobacter pylori for 12 weeks. (C) The number of fundic argyrophil cells in $\mathrm{H}$. pylori-infected Mongolian gerbils. All results are expressed as the mean \pm SEM. ${ }^{*} p<0.001$ vs control group at the same time point. (D) Immunostaining for regenerating (Reg) protein in the fundus in the $\mathrm{H}$. pylori-infected Mongolian gerbil at 36 weeks after inoculation. The number of Reg protein-positive cells was increased in the basal regions of the fundic mocosa.

infected gerbils at 12 weeks after inoculation (Fig. 6, B and $\mathrm{C}$ ). In accordance with the increase of argyrophil cells, the number of Reg protein-positive cells was also increased in $H$. pylori-infected gerbils at more than 12 weeks after inoculation (Fig. 6D). However, Reg protein-positive cells were hardly detected in the normal fundic mucosa.

\section{Changes in Reg Gene Expression in the Fundus of $\mathrm{H}$. pylori-Infected Mongolian Gerbils}

A 156-bp cDNA of Mongolian gerbil Reg was used as the probe for Northern blot analysis (Fig. 7). No Reg mRNA expression was detected in the fundus in any of the control gerbils by Northern blot analysis, although it was detected by reverse-transcription (RT)-PCR analysis (data not shown). Furthermore, no Reg mRNA expression was detected in the fundus in the $H$. pylori-infected gerbils within the first 2 weeks after inoculation. However, in the H. pylori-infected group, Reg mRNA became detectable in the fundus at 4 weeks after infection, and its levels continued to increase up to 36 weeks (Fig. 8). On the other hand, $H$. pylori eradication treatment diminished Reg mRNA expression in the fundus (Fig. 8).

\section{Relationship between Reg mRNA Expression, Serum Gastrin Levels, and the Severity of Fundic Inflammation in $\mathrm{H}$. pylori-Infected Mongolian Gerbils}

We examined the relationship between Reg mRNA expression, serum gastrin levels, and the severity of fundic inflammation in $\mathrm{H}$. pylori-infected Mongolian gerbils. Among the infected animals, serum gastrin levels correlated significantly with Reg mRNA expression levels in the fundus $(p<0.001$; Fig. 9A). Fundic inflammatory cell scores for both neutrophils and mononuclear cells also correlated significantly with Reg mRNA expression levels in the fundus $(p<0.005$ and 0.01, respectively) (Fig. 9, B and C).

\section{Gastric Cell Proliferation and Apoptosis}

Proliferating cell nuclear antigen (PCNA)-positive cells were observed mainly in the neck zone of the fundic
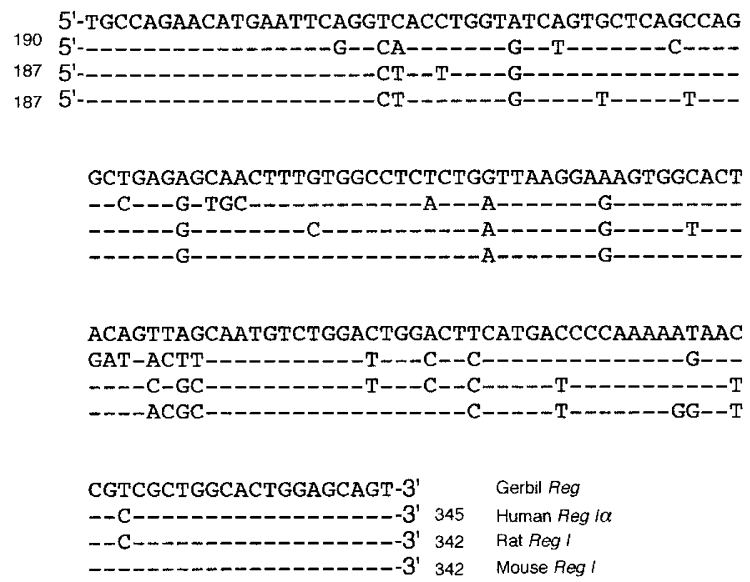

Figure 7.

Alignment of the 156-bp portion of Reg cDNA sequences for Mongolian gerbil. The bars in the sequences for human regenerating gene $(R e g) / \alpha$, rat Reg I, and mouse Reg I indicate oligonucleotides corresponding with the gerbil ones; oligonucleotide homologies of $83.3 \%, 88.5 \%$, and $89.1 \%$ were observed between the Mongolian gerbil sequence and the human, rat, and mouse sequences, respectively. 
A
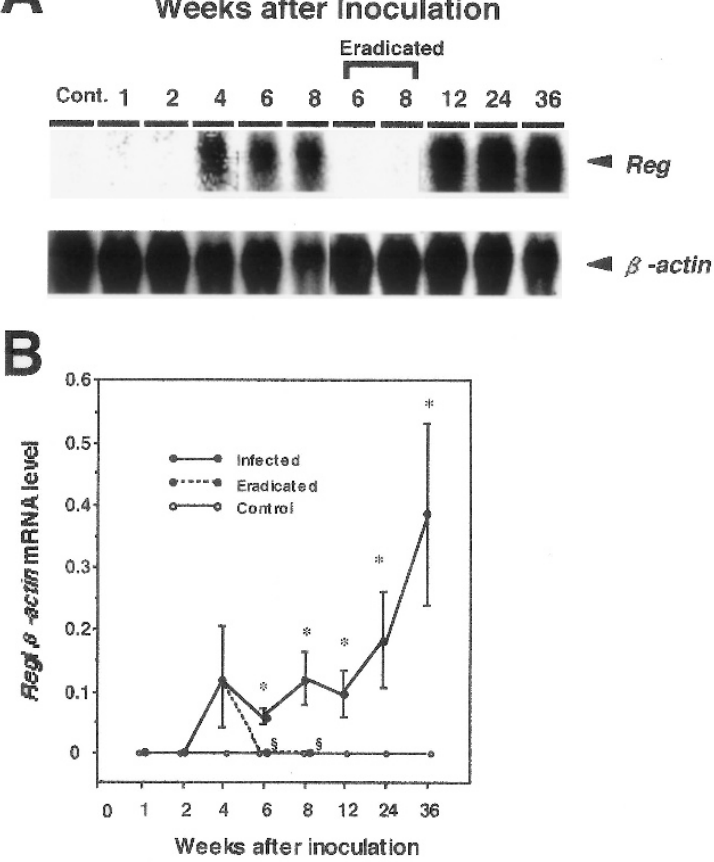

Figure 8.

Serial regenerating gene (Reg) mRNA expression levels in the fundus of Mongolian gerbils infected with Helicobacter pylori and after $H$. pylori eradication. Eradication was carried out at 4 weeks after inoculation. (A) Total fundic RNA $(30 \mu \mathrm{g})$ was extracted at the times indicated after $H$. pylori inoculation and analyzed by Northern blotting as described in the "Materials and Methods" section. No Reg mRNA signal was detected among the total fundic RNA of the control gerbils at any time throughout the experiment (data not shown). (B) The ratio of the signal intensities of Reg to $\beta$-actin mRNA were quantified using a BAS 2000 image analyzer (Fujix, Tokyo, Japan). The vertical lines represent the mean \pm SEM. ${ }^{*} p<0.05$ vs control group at the same time point. ${ }^{\S} p<0.05$ vs infected group at the same time point.

glands in the normal gastric mucosa. In contrast, they were distributed throughout the gastric mucosa in $H$. pylori-infected gerbils. The number of PCNA-positive cells in the fundic mucosa was significantly increased at more than 6 weeks after $H$. pylori inoculation. $H$. pylori eradication treatment reduced it to the control levels (Fig. 10).

TUNEL (terminal deoxynucleotidyl-mediated dexyuridine triphosphate-digoxigenin nick-end labeling) signal was mainly observed in the pit cells in the normal foveolar epithelium. In $H$. pylori-infected gerbils, TUNEL-positive cells were mainly distributed throughout the gastric mucosa. The number of TUNEL-positive cells in the fundic mucosa was significantly increased at more than 6 weeks after $H$. pylori inoculation. However, H. pylori eradication treatment reduced it to the control levels (Fig. 11).

\section{Discussion}

As we and others have previously shown, the Mongolian gerbil is a very useful animal model for studying the time courses of changes in the pathology of $H$. pylori-induced gastritis (Hirayama et al, 1996; Ikeno et al, 1999). Inflammation induced by $H$. pylori is believed to start in the pyloric mucosa and spread to the fundic mucosa. In the present study, we clearly observed this pattern of spread and, moreover, found that gastric acidity and serum gastrin levels are closely related to the pathologic changes: gastric acidity decreased in association with the spread of inflammation to the fundic mucosa, while the serum gastrin level increased in response to the reduction in gastric acidity. Regarding the reduction of gastric acidity, two possible explanations may be considered. One is that fundic inflammation may cause destruction of the acid-producing parietal cells, and the second is that ammonia generated by $H$. pylori urease may produce an alkaline environment in the stomach. In addition, recent reports suggest that IL-1 $\beta$ is produced in the mucosa during $H$. pylori-associated inflammation and that this may have an inhibitory effect on gastric acid secretion (Beales and Calam, 1998; Wallace et al, 1991). Thus, although we did not measure IL-1 $\beta$ levels in the fundic mucosa during the present study, it may be reasonable to suspect that IL-1 $\beta$ is also involved in the decrease in gastric acidity seen in $H$. pyloriinduced gastritis.

It should be emphasized that the elevation of serum gastrin levels was preceded by the reduction in gastric acidity. Mild hypergastrinemia is generally observed in patients with chronic $H$. pylori-induced gastritis (Levi et al, 1989; Mulholland et al, 1993) and, although $H$. pylori-induced gastritis has been reported to cause hypergastrinemia either directly or indirectly via the production of various cytokines (Beales et al, 1997; Calam, 1996; Lehmann et al, 1996), our present data favor the idea that reduced gastric acidity is responsible for such hypergastrinemia.

In the uninfected control group, Reg mRNA was detected in the fundus by RT-PCR but not by Northern blotting, suggesting that Reg mRNA is expressed at very low levels in the normal fundic mucosa of Mongolian gerbils. Reg mRNA is normally expressed in argyrophilic ECL cells in humans and rats (Fukui et al, 1998; Higham et al, 1999). However, only a few argyrophilic cells were present in the fundus of Mongolian gerbils as assessed by silver staining, and this is compatible with the low expression of the Reg gene in the fundus.

Recently, we have shown that both Reg gene expression and the number of Reg-positive ECL cells in the rat fundic mucosa are increased during experimental hypergastrinemia evoked by proton pump inhibitors (Fukui et al, 1998). In the present study, we have clearly shown that Reg gene expression is augmented and both argyrophilic and Reg protein-positive cell counts are increased in the fundic mucosa during $H$. pylori infection with hypergastrinemia, suggesting a close relationship between increased $R e g$ gene expression and hypergastrinemia. Interestingly, we also found that Reg mRNA expression levels correlated closely with the severity of fundic mucosal inflammation. As we and others have previously shown in vitro, certain cytokines including IL-6, IFN- $\gamma$, TNF- $\alpha$, and cytokine-induced neutrophil chemoattractant $2 \beta$ may enhance Reg gene transcription (Akiyama et al, 2001; Dusetti et al, 1996; Kazumori 
A

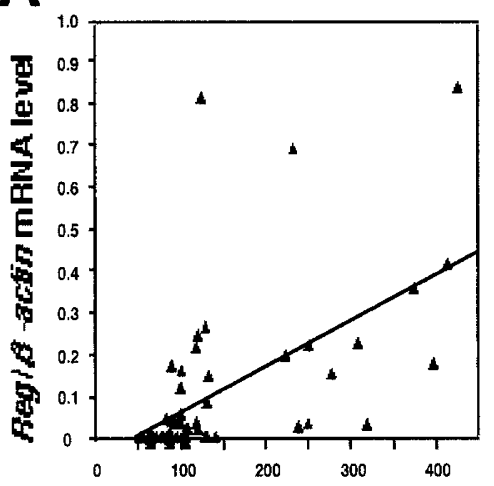

Serum gastrin (pg/ml)
B

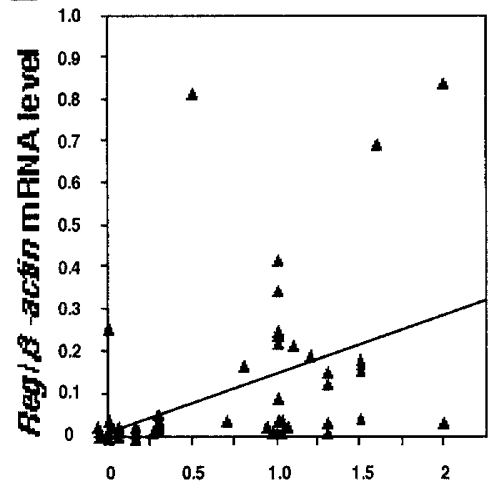

Score of neutrophil cell infiltration
C

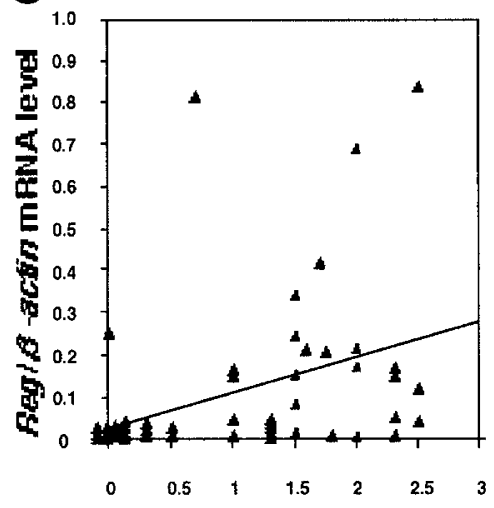

Score of mononuclear cell infiltration

Figure 9.

Relationships between fundic regenerating gene (Reg) mRNA expression levels and (A) serum gastrin levels or scores for (B) neutrophil and (C) mononuclear cell infiltration in the fundus in Helicobacter pylori-infected Mongolian gerbils $(n=49)$. The fundic Reg mRNA expression levels correlated significantly with the serum gastrin level $(p<0.001, r=0.54)$ and scores for neutrophil $(p<0.005, r=0.40)$ and mononuclear cell $(p<0.01, r=0.37)$ infiltration in the $H$. pylori-infected gerbils.
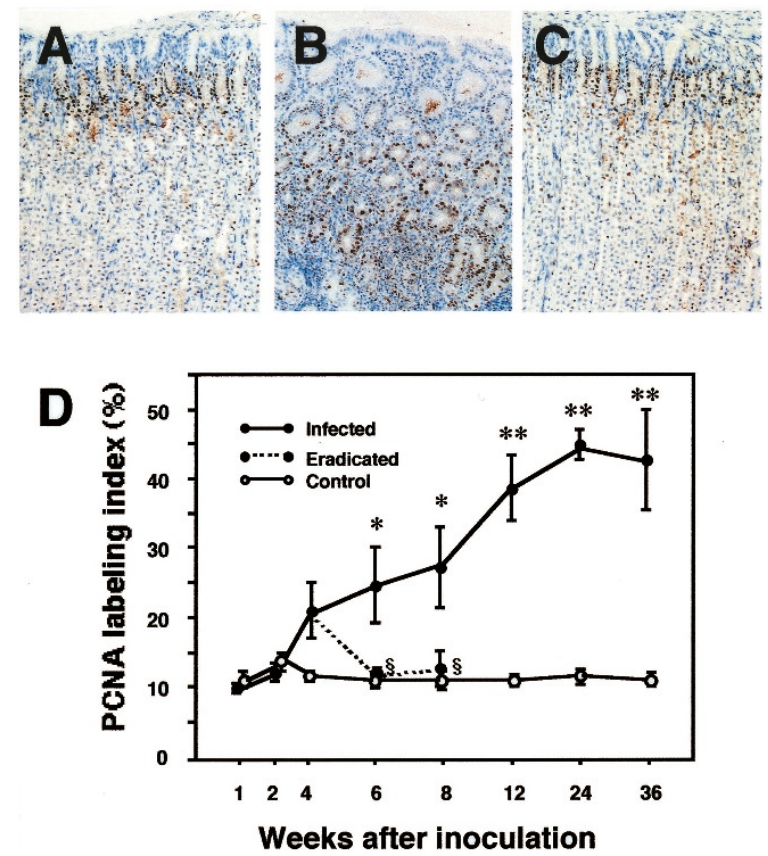

Figure 10.

Immunostaining of PCNA in the fundic mucosa of Mongolian gerbils infected with Helicobacter pylori and after $\mathrm{H}$. pylori eradication. (A) Normal fundic mucosa $(\times 100)$. (B) Fundic mucosa of gerbil infected with H. pylori for 12 weeks $(\times 100)$. (C) Fundic mucosa of gerbils 4 weeks after $H$. pylorieradication $(\times 100)$. (D) Serial PCNA labeling index in the fundus of Mongolian gerbils infected with $H$. pylori and after $H$. pylori eradication. All results are expressed as the mean \pm SEM. ${ }^{\star} p<0.05,{ }^{*} p<0.01$ vs control group at the same time point. ${ }^{\S} p<0.05$ vs infected group at the same time point.

et al, 2000). Because these cytokines are apparently involved in $H$. pylori-induced gastritis (Bodger and Crabtree, 1998; Calam, 1996; Genta, 1997), they (as well as hypergastrinemia) may have enhanced Reg gene expression in our study. On the other hand, during $H$. pylori-induced gastritis, the gastric epithelial cells are continuously being injured by inflammation and subsequently regenerated, and it has been re-
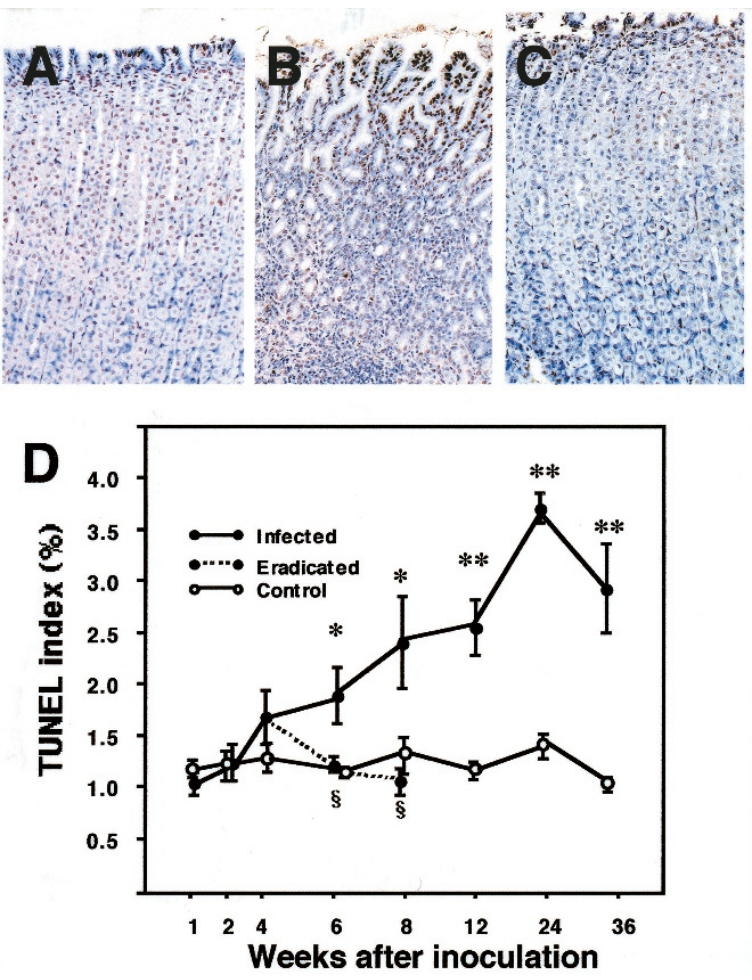

Figure 11.

TUNEL (terminal deoxynucleotidyl-mediated dexyuridine triphosphatedigoxigenin nick-end labeling) apoptotic cell detection in the fundic mucosa of Mongolian gerbils infected with Helicobacter pylori and after $H$. pylori eradication. (A) Normal fundic mucosa $(\times 100)$. (B) Fundic mucosa of gerbils infected with $H$. pylori for 12 weeks $(\times 100)$. (C) Fundic mucosa of gerbils 4 weeks after $H$. pylori eradication $(\times 100)$. (D) Serial TUNEL index in the fundus of Mongolian gerbils infected with $H$. pylori and after $H$. pylori eradication. All results are expressed as the mean \pm SEM. ${ }^{\star} p<0.05,{ }^{\star *} p<0.01$ vs control group at the same time point. ${ }^{\S} p<0.05$ vs infected group at the same time point.

ported that the Reg gene is induced during the healing of stomach tissue (Asahara et al, 1996; Kawanami et al, 1997, Kazumori et al, 2000). Thus, it is tempting to speculate that the Reg gene is involved in the regen- 
eration of gastric epithelial cells during $H$. pyloriinduced gastritis. In support of this theory, we have previously shown Reg protein to have a trophic effect on gastric epithelial cells (Fukui et al, 1998); moreover, others have demonstrated that the Reg-related protein, PAP, exerts an anti-apoptotic effect in vitro (Ortiz et al, 1998). Both proliferation and apoptosis of gastric epithelial cells are actively occurring in $H$. pyloriinduced gastritis (Jones et al, 1997; Peek et al, 1997). Indeed, in our present study, we clearly showed enhancement of not only apoptosis but also proliferation of the gastric mucosal cells in $H$. pylori-infected gerbils. Thus, the Reg gene product may function as a trophic and/or an antiapoptotic factor in the H. pyloriinfected gastric mucosa.

Although $H$. pylori infection is epidemiologically associated with the development of gastric cancer (Parsonnet et al, 1991), the mechanism by which this occurs is still unclear. However, because gastrin has a trophic effect on gastric epithelial cells, hypergastrinemia might play a role in $H$. pylori-induced gastric carcinogenesis. Interestingly, Wang et al (2000) have recently suggested that hypergastrinemia and $H$. pylori infection have synergistic effects that contribute toward progression to gastric cancer. Moreover, Hirayama et al (1999) have shown that poorly differentiated adenocarcinomas as well as carcinoid tumors develop during $H$. pylori-induced gastritis with hypergastrinemia. Recent studies have shown that gastrin receptors are present on gastric mucosal progenitor cells, suggesting that gastrin has direct trophic actions on gastric mucosal cells (Kazumori et al, 2001; Nakajima et al, 2002). On the other hand, several investigators have reported that gastrin promotes gastric mucosal cell proliferation indirectly by stimulating the production of growth factors such as TGF- $\alpha$, heparinbinding epidermal growth factor-like growth factor, and Reg (Fukui et al, 1998; Miyazaki et al, 1999; Wang et al, 2000). Taking these possibilities together, it appears that gastrin may promote gastric tumorigenesis by acting both directly on gastric mucosal cells and indirectly by enhancing Reg protein production.

In conclusion, we have shown that Reg gene expression is enhanced in $H$. pylori-induced gastritis and that expression levels of this gene are closely related to serum gastrin levels and the severity of fundic mucosal inflammation. These data suggest that Reg is induced by gastrin and/or inflammation, and may promote gastric mucosal proliferation in $H$. pyloriinduced gastritis.

\section{Materials and Methods}

\section{Animals and H. pylori Strain}

Eight-week-old male Mongolian gerbils weighing 30 to 50 g (Harlan Sprague Dawley, Inc., Indianapolis, Indiana) were used. They were housed in an airconditioned biohazard room and had free access to food and water. The experimental protocol was approved by the Animal Care Committee of Baylor College of Medicine. H. pylori CA20, the strain used for inoculation of the gerbils in this study, was originally isolated from a gastric cancer patient. This strain $\left(\mathrm{cagA}^{+}\right.$, vacA s1m2) was identified by its morphology; Gram's staining; and its urease, catalase, and oxidase activities. Prior to inoculation, the $H$. pylori was grown in brain-heart infusion broth containing $7 \%$ fetal bovine serum at $37^{\circ} \mathrm{C}$ under microaerobic conditions.

\section{Experimental Design}

After fasting for 24 hours, 61 gerbils were inoculated with $1 \mathrm{ml}$ culture broth containing $10^{9}$ colony-forming units $H$. pylori via a gastric tube. A further 44 gerbils received $1 \mathrm{ml}$ culture broth alone and served as uninfected controls. Four weeks after inoculation, 12 infected gerbils were administrated orally with lansoprazole, amoxicillin, and clarithromycin (10, 3, and 30 $\mathrm{mg} / \mathrm{kg}$ body weight, respectively), suspended in $0.5 \%$ w/w carboxymethylcellulose sodium solution, bid for 2 days (Shimizu et al, 2000). Both infected and uninfected gerbils were killed at 1, 2, 4, 6, 8, 12, 24, and 36 weeks after inoculation. The gerbils that had undergone $H$. pylori eradication were killed at 6 and 8 weeks after inoculation (ie, 2 and 4 weeks after eradication). To ascertain $H$. pylori infection and its eradication, part of the gastric tissues were homogenized in brain-heart infusion broth and cultured as previously reported (Dore et al, 2001; Yamaoka et al, 1999). The experimental schedules, including the number of gerbils in each group killed at each time point, are summarized in Figure 1.

\section{Gastric Acidity and Serum Gastrin Concentrations}

After a 24-hour fast, the gerbils were killed and their entire gastric contents were collected by clamping the esophageal and duodenal ends of the stomach (Dial et al, 2000). The gastric juice was then separated from the gastric contents by centrifugation $(10,000 \mathrm{rpm}, 1$ minute). The acidity of the gastric juice was measured by titration with $0.01 \mathrm{~N} \mathrm{NaOH}$ on a titrator (TTT60 Titrator; The London Company, Ohio). In addition, blood was collected from a cardiac puncture at the time of death. The serum was stored at $-20^{\circ} \mathrm{C}$ until assayed for gastrin as described previously (Bloom and Long, 1982).

\section{Histopathology}

After collecting the gastric contents and blood, the stomach of each gerbil was opened along the greater curvature. After macroscopic observations, the stomachs were fixed in $10 \%$ buffered formalin, sliced along the longitudinal axis into seven slips of equal width, embedded in paraffin, and cut into $4-\mu \mathrm{m}$ sections. The sections were stained with hematoxylin and eosin for morphologic observations and by Genta's staining method for the detection of $H$. pylori, as previously described (Genta et al, 1994). The degree of gastritis in the antrum and corpus was graded according to the Updated Sydney system (Dixon et al, 1996). Histologic parameters, including neutrophil infiltration, mononuclear cell infiltration, atrophy, and density of $H$. pylori 
colonization, were scored on a scale of 0 to 3 as follows: grade 0 , normal (none in case of $H$. pylori colonization); grade 1, mild; grade 2, moderate; grade 3 , marked. The scores were evaluated in all of the slips from each stomach, and the results were averaged. Fundic argyrophil cells were also evaluated using the standard Grimelius' silver staining method. The number of fundic argyrophil cells was counted in at least 10 well-orientated visual fields (magnification, $\times 100$ ) on seven different sections, and the average per visual field was calculated. In addition, immunohistochemical staining for Reg protein was performed with the avidin-biotin-complex immunoperoxidase method using antirat Reg antibody (dilution 1:500), as previously described (Fukui et al, 1998).

\section{Gastric Cell Proliferation and Apoptosis}

The tissue sections of the fundic mucosa were used for immunostaining of PCNA. In brief, the sections were deparaffinized, rehydrated, and then pretreated with $3 \% \mathrm{H}_{2} \mathrm{O}_{2}$ in methanol for 30 minutes at room temperature to quench endogenous peroxidase activity. The sections were incubated with $1 \%$ BSA in PBS (PBS) for 20 minutes and then incubated with an anti-PCNA antibody (PC10, Dako, Kyoto, Japan; dilution, 1:500) for 60 minutes at $37^{\circ} \mathrm{C}$. Thereafter, sections were immunostained using a LSAB kit (Dako, Marseille, France) in accordance with the supplied protocol, visualized by 3,3'-diaminobenzidine tetrahydrochloride, and counterstained with Mayer hematoxylin. Five-hundred epithelial cells were counted in five different visual fields (magnification, $\times 100$ ) on each section. PCNA labeling index was calculated as the percentage of positive cells.

The tissue sections of the fundic mucosa were also used for TUNEL assay using an in situ cell death detection kit (Roche, Mannheim, Germany). In brief, the sections were deparaffinized, rehydrated, and then incubated with proteinase $\mathrm{K}(20 \mu \mathrm{g} / \mathrm{ml})$ for 15 minutes at $37^{\circ} \mathrm{C}$. The sections were then washed in PBS, and endogenous peroxidase was blocked by $3 \% \mathrm{H}_{2} \mathrm{O}_{2}$ in methanol for 30 minutes at room temperature. After washing in PBS, slides were incubated with terminal transferase buffer and reaction mixture for 60 minutes at $37^{\circ} \mathrm{C}$. The sections were then washed in PBS and incubated with peroxidase-conjugated Fab fragments of anti-fluorescein at $37^{\circ} \mathrm{C}$ for 30 minutes. The slides were washed in PBS, visualized by 3,3'diaminobenzidine tetrahydrochloride, and counterstained with Mayer hematoxylin. Five-hundred epithelial cells were counted in five different visual fields (magnification, $\times 100$ ) on each section. TUNEL index was calculated as the percentage of positive cells.

\section{Sequence Analysis of Mongolian Gerbil Reg Gene}

Total RNA was isolated from the pancreas of a Mongolian gerbil using Trizol Reagent (Gibco BRL, Rockville, Maryland). To generate cDNA, $4 \mu \mathrm{g}$ of total RNA was reverse-transcribed using $200 \mathrm{U}$ of SuperScript II $\mathrm{RT}$ (Gibco BRL) in a total reaction volume of $20 \mu \mathrm{L}$.
Then, to identify Mongolian gerbil Reg cDNA clones, we searched similar parts of the sequence among murine, rat, and human Reg cDNA and chose a forward primer (corresponding to human Reg positions 190-206) and a reverse primer (positions 328345) for PCR (Fig. 7). One $\mu$ l of reverse-transcription product (cDNA) was amplified by PCR in a $20-\mu l$ reaction volume containing $40 \mathrm{pmol}$ of above set of primers, $1.25 \mathrm{U}$ of Ampli-TaqDNA polymerase (Applied Biosystems, Brunchburg, New Jersey), and final concentration of PCR buffer (20 mM Tris- $\mathrm{HCl}$ [pH 8.4], $50 \mathrm{~mm} \mathrm{KCl}$ ), $2.5 \mathrm{~mm} \mathrm{MgCl}_{2}, 10 \mathrm{~mm}$ DTT, and $1 \mathrm{~mm}$ dNTP. The PCR amplification was performed as follows: at $95^{\circ} \mathrm{C}$ for 5 minutes, once; 35 cycles of $94^{\circ} \mathrm{C}$ for 30 seconds, $50^{\circ} \mathrm{C}$ for 30 seconds, and $72^{\circ} \mathrm{C}$ for 1 minute; and then at $72^{\circ} \mathrm{C}$ for 7 minutes. The PCR product was ligated into pGEM-T Easy vector (Promega, Madison, Wisconsin), and the nucreotide sequence of the insert was determined by the dideoxy chain termination procedure (Sanger et al, 1977) (Fig. 7).

\section{Northern Blot Analysis}

Extracted RNA from the fundus of Mongolian gerbils was separated by electrophoresis in $0.66 \mathrm{M}$ formaldehyde/1\% agarose gel. After transfer to a nitrocellulose membrane (Schleicher \& Schuell, Germany), the nucleic acids were fixed to the membrane by UV crosslinking. The probes used for Northern blot analysis were a 156-bp cDNA of Mongolian gerbil Reg (Fig. 7) and a 164-bp cDNA of Mongolian gerbil $\beta$-actin (Takashima et al, 2001). Radiolabeling of the probes was performed with $\left[\alpha^{-}{ }^{32} \mathrm{P}\right]$ deoxycytidine triphosphate using a random primer labeling kit (Amersham Pharmacia Biotech, Buckinghamshire, United Kingdom). Hybridization was performed at $42^{\circ} \mathrm{C}$, and filters were washed twice at $55^{\circ} \mathrm{C}$ in $0.1 \times$ standard saline citrate plus $0.1 \%$ sodium dodecyl sulfate as described previously (Fukui et al, 1998). The radiolabeled DNA probe was detected by a bioimage analyzer (BAS 2000, Fujix, Tokyo, Japan).

\section{Statistical Analysis}

All values were expressed as the mean \pm SEM. Statistical differences between two animal groups were assessed by the unpaired Student's $t$ test or MannWhitney $U$ test when data was not parametric. The relationship between Reg mRNA levels and serum gastrin levels or fundic inflammatory scores were assessed by linear regression analysis.

\section{Acknowledgements}

We are grateful to Dr. Michael S. Osato, Gastroenterology Microbiology Laboratory, Department of Medicine, Veterans Affairs Medical Center, Houston, Texas, for providing $H$. pylori strain CA20; and Dr. Hiroshi Okamoto, Tohoku University Graduate School of Medicine, Sendai, Japan, for providing anti-Reg antibody. 


\section{References}

Akiyama T, Takasawa S, Nata K, Kobayashi S, Abe M, Shervani NJ, Ikeda T, Nakagawa K, Unno M, Matsuno S, and Okamoto H (2001). Activation of Reg gene, a gene for insulin-producing $\beta$-cell regeneration: Poly(ADP-ribose) polymerase binds Reg promoter and regulates the transcription by autopoly(ADP-ribosyl)ation. Proc Nathl Acad Sci USA 98:48-53.

Asahara M, Mushiake S, Shimada S, Fukui H, Kinoshita Y, Kawanami C, Watanabe T, Tanaka S, Ichikawa A, Uchiyama Y, Narushima Y, Takasawa S, Okamoto H, Tohyama M, and Chiba T (1996). Reg gene expression is increased in rat gastric enterochromaffin-like cells following water-immersion stress. Gastroenterology 111:45-55.

Beales IL and Calam J (1998). Interleukin $1 \beta$ and tumor necrosis factor $\alpha$ inhibit acid secretion in cultured rabbit parietal cells by multiple pathways. Gut 42:227-234.

Beales I, Blaser MJ, Srinivasan S, Calam J, Pérez- Pérez GI, Yamada T, Scheiman J, Post L, and DelValle J (1997). Effect of Helicobacter pylori products and recombinant cytokines on gastrin release from cultured canine $\mathrm{G}$ cells. Gastroenterology 113:465-471.

Bloom SR and Long RG (1982). Radioimmunoassay of gut regulatory peptides. Philadelphia: Saunders.

Bodger K and Crabtree JE (1998). Helicobacter pylori and gastric inflammation. Br Med Bull 54:139-150.

Calam J (1996). Helicobacter pylori and hormones. Yale J Biol Med 69:39-49.

De Caro AM, Bonicel JJ, Rouimi P, De Caro JD, Sarles H, and Rovery M (1987). Complete amino acid sequence of an immunoreactive form of human pancreatic stone protein isolated from pancreatic juice. Eur J Biochem 168:201-207.

Dial EJ, Hall LR, Romero JJ, Lechago J, Fox JG, and Lichtenberger LM (2000). Altered gastrin regulation in mice infected with Helicobacter felis. Dig Dis Sci 45:1308-1314.

Dixon MF, Genta RM, Yardley JH, and Correa P (1996). Classification and grading of gastritis: The updated Sydney system. Am J Surg Pathol 20:1161-1181.

Dore MP, Sepulveda AR, El-Zimaity H, Yamaoka Y, Osato MS, Kato M, Nieddu AM, Realdi G, and Graham DY (2001). Isolation of Helicobacter pylori from seep: Implications for transmission to human. Am J Gastroenterol 96:1396-1401.

Dusetti NJ, Mallo GV, Ortiz EM, Keim V, Dagorn J-C, and lovanna JL (1996). Induction of lithostathine/reg mRNA expression by serum from rats with acute pancreatitis and cytokines in pancreatic acinar AR-42J cells. Arch Biochem Biophys 330:129-132.

Fukui H, Kinoshita Y, Maekawa T, Okada A, Waki S, Hassan S, Okamoto H, and Chiba T (1998). Regenerating gene protein may mediate gastric mucosal proliferation induced by hypergastrinemia in rats. Gastroenterology 115:1483-1493.

Genta RM (1997). The immunobiology of Helicobacter pylori gastritis. Semin Gastrointest Dis 8:2-11.

Genta RM, Robason GO, and Graham DY (1994). Simultaneous visualization of Helicobacter pylori and gastric morphology: A new stain. Hum Pathol 25:221-226.

Giorgi D, Bernard J-P, Rouquier S, lovanna JL, and Dagorn J-C (1989). Secretory pancreatic stone protein messenger RNA. J Clin Invest 84:100-106.
Hersey SJ and Sachs J (1995). Gastric acid secretion. Physiol Rev 75:155-189.

Higham AD, Bishop LA, Dimaline R, Blackmore CG, Dobbins AC, Varro A, Thompson DG, and Dockray GJ (1999). Mutation of Regl $\alpha$ are associated with enterochromaffin-like cell tumor development in patients with hypergastrinemia. Gastroenterology 116:1310-1381.

Hirayama F, Takagi S, Iwao E, Yokoyama Y, Haga K, and Hanada S (1999). Development of poorly differentiated adenocarcinoma and carcinoid due to long-term Helicobacter pylori colonization in Mongolian gerbils. J Gastroenterol $34: 450-454$

Hirayama F, Takagi S, Yokoyama Y, Iwao E, and Ikeda Y (1996). Establishment of gastric Helicobacter pylori infection in Mongolian gerbils. J Gastroenterol 31(Suppl 9):24-28.

Ikeno $\mathrm{T}$, Ota $\mathrm{H}$, Sugiyama A, Ishida K, Katsuyama T, Genta RM, and Kawasaki S (1999). Helicobacter pylori-induced chronic active gastritis, intestinal metaplasia, and gastric ulcer in Mongolian gerbils. Am J Pathol 154:951-960.

Jones NL, Shannon PT, Cutz E, Yeger H, and Sherman PM (1997). Increase in proliferation and apoptosis of gastric epithelial cells early in the natural history of Helicobacter infection. Am J Pathol 151:1695-1703.

Kawanami C, Fukui H, Kinoshita Y, Nakata H, Asahara M, Matsushima Y, Kishi K, and Chiba T (1997). Regenerating gene expression in normal gastric mucosa and indomethacin-induced mucosal lesions of the rat. J Gastroenterol 32:12-18.

Kazumori H, Ishihara S, Hoshino E, Kawashima K, Moriyama $\mathrm{N}$, Suetsugu H, Sato H, Adachi K, Fukuda R, Watanabe M, Takasawa S, Okamoto H, Fukui H, Chiba T, and Kinoshita $Y$ (2000). Neutrophil chemoattractant $2 \beta$ regulate expression of the Reg gene in injured gastric mucosa in rats. Gastroenterology 119:1610-1622.

Kazumori H, Ishihara S, Kawashima K, Fukuda R, Chiba T, and Kinoshita $Y$ (2001). Analysis of gastrin receptor gene expression in proliferating cells in the neck zone of gastric fundic glands using laser capture microdissection. FEBS Lett 489:208-214.

Kinoshita Y, Nakata H, Kishi K, Kawanami C, Sawada M, and Chiba T (1998). Comparison of the signal transduction pathways activated by gastrin in enterochromaffin-like and parietal cells. Gastroenterology 115:93-100.

Lehmann FS, Golodner EH, Wang J, Chen MC, Avedian D, Calam J, Walsh JH, Dubinett S, and Soll AH (1996). Mononuclear cells and cytokines stimulate gastrin release from canine antral cells in primary culture. Am J Physiol 270: G783-G788.

Levi S, Haddad G, Ghosh P, Beardshall K, Playford R, and Calam J (1989). Campylobacter pylori and duodenal ulcers: The gastrin link. Lancet 1:1167-1168.

Marshall BJ and Warren JR (1984). Unidentified curved bacilli in the stomach of patients with gastritis and peptic ulceration. Lancet 1:1311-1315.

McGowan CC, Cover TL, and Blaser MJ (1996). Helicobacter pylori and gastric acid: Biological and therapeutic implications. Gastroenterology 110:926-938.

Miyazaki Y, Shinomura Y, Tsutsui S, Zushi S, Higashimoto Y, Kanayama S, Higashiyama S, Taniguchi N, and Matsuzawa $Y$ (1999). Gastrin induces heparin-binding epidermal growth 
factor-like growth factor in rat gastric epithelial cells transfected with gastrin receptor. Gastroenterology 116:78-89.

Mulholland G, Ardill JE, Fillmore D, Chittajallu RS, Fullarton GM, and McColl KE (1993). Helicobacter pylori related hypergastrinemia is the result of selective increase in gastrin 17. Gut 34:757-761.

Nakajima T, Konda Y, Izumi Y, Kanai M, Hayashi N, Chiba T, and Takeuchi T (2002). Gastrin stimulates the growth of gastric pit cell precursors by inducing its own receptors. Am J Physiol 282:G359-G366.

Ortiz EM, Dusetti NJ, Vasseur S, Malka D, Bödeker H, Dagorn J-C, and lovanna JL (1998). The pancreatitis-associated protein is induced by free radicals in AR4-2J cells and confers cell resistance to apoptosis. Gastroenterology 114: 808-816.

Parsonnet J, Friedman GD, Vandersteen DP, Chang Y, Vogelman JH, Orentreich N, and Sibley RK (1991). Helicobacter pylori infection and the risk of gastric carcinoma. N Engl J Med 325:1127-1131.

Peek RM Jr., Moss SF, Tham KT, Perez-Perez GI, Wang S, Miller GG, Atherton JC, Holt PR, and Blaser MJ (1997). Helicobacter pylori cagA ${ }^{+}$strains and dissociation of gastric epithelial cell proliferation from apoptosis. J Natl Cancer Inst 89:863-868.

Rouquier S, Giorgi D, lovanna J, and Dagorn J-C (1989). Sequence similarity between the reg transcript and pancreatic stone protein mRNA. Biochem J 264:621-624.

Sanger F, Nicklen S, and Coulson AR (1977). DNA sequencing with chain terminating inhibitors. Proc Natl Acad Sci USA 74:5463-5467.
Shimizu N, Ikehara Y, Inada K, Nakanishi H, Tsukamoto T, Nozaki K, Kaminishi M, Kuramoto S, Sugiyama A, Katsuyama $\mathrm{T}$, and Tatematsu M (2000). Eradication diminishes enhancing effects of Helicobacter pylori infection on glandular stomach carcinogenesis in Mongolian gerbils. Cancer Res 60: 1512-1514.

Takashima M, Furuta T, Hanai H, Sugimura H, and Kaneko E (2001). Effects of Helicobacter pylori infection on gastric acid and serum gastrin levels in Mongolian gerbils. Gut 48:765773.

Terazono K, Yamamoto H, Takasawa S, Shiga K, Yonemura $\mathrm{Y}$, Tochino $\mathrm{Y}$, and Okamoto $\mathrm{H}$ (1988). A novel gene activated in regenerating islets. $\mathrm{J}$ Biol Chem 263:2111-2114.

Wallace JL, Cucala M, Mugridge K, and Parente L (1991). Secretagogue-specific effects of interleukin-1 on gastric acid secretion. Am J Physiol 261:G559-G564.

Wang TC, Dangler CA, Chen D, Goldenring JR, Koh T, Raychowdhury R, Coffey RJ, Ito S, Varro A, Dockray GJ, and Fox JG (2000). Synergistic interaction between hypergastrinemia and Helicobacter infection in a mouse model of gastric cancer. Gastroenterology 118:36-47.

Watanabe $\mathrm{T}$, Yonemura $\mathrm{Y}$, Yonekura $\mathrm{H}$, Suzuki $\mathrm{Y}$, Miyashita $\mathrm{H}$, Sugiyama K, Morizumi S, Unno M, Tanaka O, Kondo H, Bone AJ, Takasawa S, and Okamoto H (1994). Pancreatic beta-cell replication and amelioration of surgical diabetes by Reg production. Proc Natl Acad Sci USA 91:3589-3592.

Yamaoka Y, Komada T, Gutierrez O, Kim JG, Kashima K, Graham DY (1999). Relationship between Helicobacter pylori ice A, cagA, and vacA status and clinical outcome: Studies in four different countries J Clin Microbiol 37:2274-2279. 